\title{
TQM and market orientation's impact on SMEs' performance
}

\author{
Hadi Abdollahi ${ }^{a^{*}}$, Kamal Razm ${ }^{\mathrm{b}}$ and Hamid Rouin $\operatorname{Tan}^{\mathrm{b}}$
}

${ }^{a}$ M.A. Student of Business Management, Allameh Tabatabaei University, Tehran, Iran

${ }^{b}$ M.A. of Business Management, Allameh Tabatabaei University, Tehran, Iran

\section{H R O N I C L E}

Article history:

Received December 28, 2013

Accepted 28 March 2014

Available online

April 32014

Keywords:

$T Q M$

Organizational performance

SMES

Market orientation

\section{A B S T R A C T}

This paper presents an empirical investigation to study the impact of total quality management (TQM) as well as market orientation on organizational performance on some Iranian small and medium enterprises (SMEs). The study designs a questionnaire in Likert scale and distributes it among some experts in city of Shiraz, Iran. Using structural equation modeling, the study determines that three components of market orientation including intelligence generation, intelligence dissemination, and responsiveness through TQM influences on organizational performance components including financial and non-financial performance as well as efficiency. In addition, TQM components including training, process management, supplier quality management, employee relationships, quality of data and reports and top management commitment influence positively on organizational performance in SMEs.

\section{Introduction}

Organizational performance is normally influenced by various factors such as human resources, good supply chain management, etc. and there are various studies to investigate the relationship between organizational performance and other important factors (Li et al., 2006, 2008; Liao et al., 2011). Demirbag et al. (2006) determined the effect of market orientation (MO) and implementation of total quality management (TQM) on organizational performance of small and medium enterprises (SMEs). They reported that, while MO had a strong and positive effect on the extent of TQM implementation, it had no significant effect on organizational performance. They also reported a strong and positive relationship between the level of TQM implementation and organizational performance. Finally, they reported that the MO had a positive and significant effect on organizational performance through only a mediating role of TQM implementation. 
Wang et al. (2012) adopted the Input-Processing-Output (IPO) concept model to build a model and reported that TQM positively influences hotel performance and MO positively influences hotel performance as well. In their survey, market orientation maintained the mediating effect between TQM and hotel performance and external environment factors played a moderator between TQM, market orientation and hotel performance, especially when external environment factors bigger changes were going to help to construct relationship with customer, to enhance hotel performance and further to achieve the success for hotel industry.

Raju et al. (2011) investigated MO specifically in the context of SMEs. They performed an in-depth review of the extant literature to develop a conceptual framework by exploring the major antecedents of MO, the MO-Performance relationship, and the key mediators and environmental moderators of this relationship. They also examined various studies on SMEs in terms of different perspectives of this framework.

Bayraktar et al. (2009) examined a framework detecting the causal links among supply chain management (SCM) and information systems (IS) practices, SCM-IS related inhibiting factors and operational performance in Turkey. They also investigated the moderating impact of SCM and IS related enabling factors on the relationships. They reported that both SCM and IS practices positively and significantly impact on the operational performance. They also reported a strong support for negative relationships between SCM-IS related inhibitors and the implementation levels of both SCM and IS practices. In addition, a strong support was detected for the hypothesized negative relationship between SCM-IS inhibitors and operational performance of SMEs.

González-Benito and González-Benito (2005) considered the effects of cultural and operational approaches for measuring market orientation; the objective and subjective measures of performance; and the source of information in the organization, specifically the perspective of production and operations. They reported a positive relationship for operational market orientation and subjective performance. In addition, the adoption of 'operational recipes' of market orientation by the production and operations function appeared to improve organizational performance regardless of the existence of any cultural support for market orientation.

\section{The proposed study}

This paper presents an empirical investigation to study the impact of total quality management (TQM) as well as market orientation on organizational performance on some Iranian small and medium enterprises (SMEs). The study designs a questionnaire in Likert scale and distributes it among some experts in city of Shiraz, Iran. The proposed study considers the following four hypotheses,

1. Market orientation maintains a positive and meaningful impact on TQM on SMEs.

2. Market orientation maintains a positive and meaningful impact on organizational performance on SMEs.

3. A good TQM implementation had positive and meaningful impact on organizational performance on SMEs.

4. TQM is a mediator on relationship between market orientation and business performance.

Fig. 1 demonstrates the structural of the proposed study of this paper. 


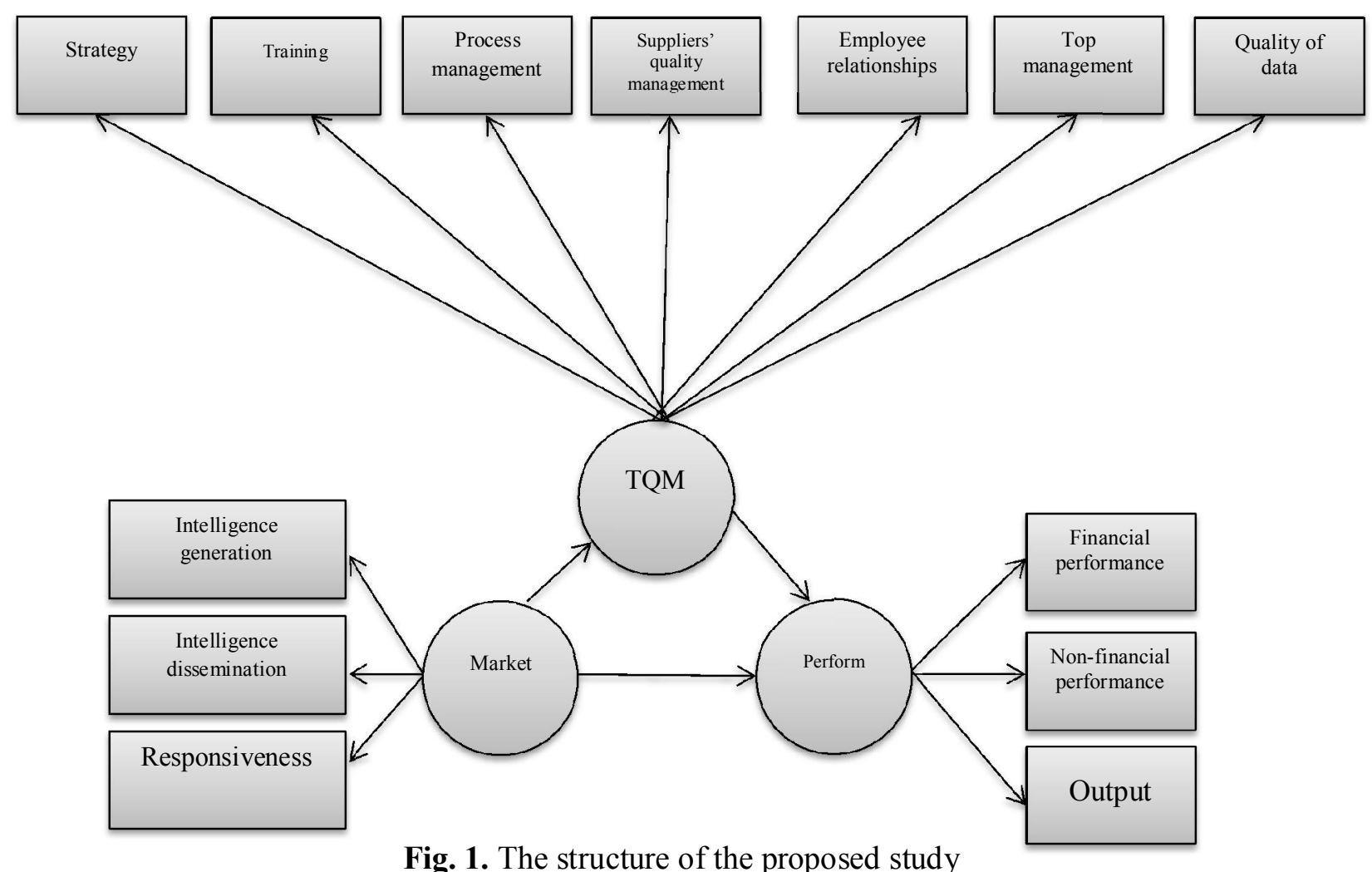

Fig. 1. The structure of the proposed study

According to Fig. 1, three components of market orientation (Market) including intelligence generation (INGEN), intelligence dissemination (INDISS), and responsiveness (RESPONSE) influences positively on TQM and organizational performance (Perform) including financial performance (FINAN), non-financial performance (NONFIN) and output (OUTPUT). In addition, in Fig. 1, there are seven components associated with TQM including training, process management, suppliers' quality management (SQM), employee relationships (EMR), quality of data and reports (QDR) and top management commitment (QUP). The proposed study uses a standard questionnaire introduced originally by Demirbag et al. (2006) in Likert scale. The study uses structural equation modeling for the analysis of the data and the results are validated based on Cronbach alpha and some other statistical test. The sample size is calculated as follows,

$N=Z_{\alpha / 2}^{2} \frac{p \times q}{e^{2}}$,

where $N$ is the sample size, $p=1-q$ represents the probability, $z_{\alpha / 2}$ is CDF of normal distribution and finally $\varepsilon$ is the error term. For our study we assume $p=0.5, z_{\alpha / 2}=1.96$ and $e=0.05$, the number of sample size is calculated as $N=386$. The propsoed study has distributed 400 questinnaires among experts who resided in city of Shiraz, Iran. Fig. 1 shows details of the personal characteristics of the participants. As we can observe from the results of Fig. 1, 81\% of the participants were male and only $19 \%$ of them were female. In terms of age, most of the participants were middle age, married and highly educated people. 


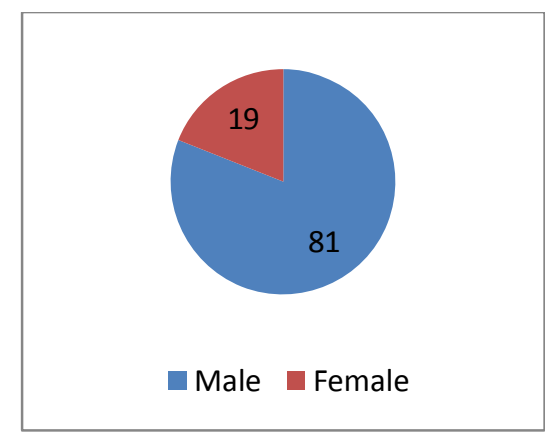

Gender

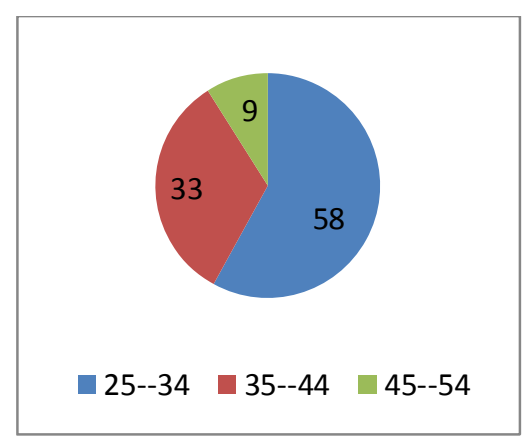

Age

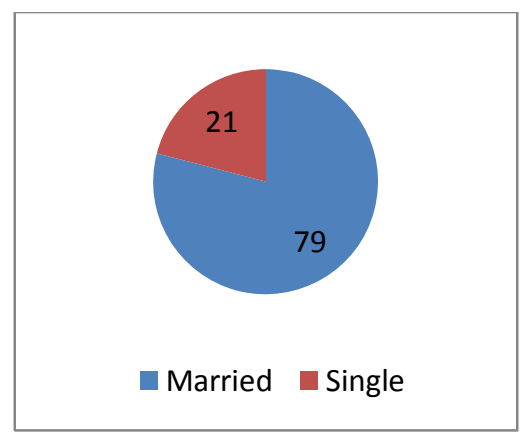

Marital status

Fig. 1. Personal charactersitics of the participants

Table 1 shows details of Cronbach alpha and AVE for different components of the survey.

\section{Table 1}

The summary of mean factor loading and AVE

\begin{tabular}{clccc}
\hline Priority & Variable & Cronbach alpha & AVE & Mean of factor loading \\
\hline 1 & Intelligence generation & 726 & 0.43 & 0.62 \\
2 & Intelligence dissemination & 739 & 0.46 & 0.65 \\
3 & Responsiveness & 706 & 0.59 & 0.63 \\
4 & Quality of data & 793 & 0.56 & 0.58 \\
5 & The role of Top management & 817 & 0.55 & 0.62 \\
6 & Employee relationships & 827 & 0.45 & 0.66 \\
7 & Supplier relationships & 764 & 0.53 & 0.56 \\
8 & Training & 822 & 0.61 & 0.79 \\
9 & Qualitative strategies & 751 & 0.59 & 0.75 \\
10 & Process management & 822 & 0.54 & 0.78 \\
11 & Financial performance & 780 & 0.66 & 0.63 \\
12 & Non-financial performance & 769 & 0.42 & 0.67 \\
\hline 13 & Output & 710 & 0.5 & \\
\hline
\end{tabular}

We have applied structural equation modeling and Table 2 demonstrates the summary of some basic statistics associated with the SEM implementation.

Table 2

The summary of some basic statistics associated with SEM implementation

\begin{tabular}{lcc}
\hline Attribute & Value & Desirable limit \\
\hline Chi-Square/df & 2.36 & Less than 3 \\
GFI & 0.917 & Greater than 0.9 \\
RMSEA & 0.098 & Less than 0.1 \\
CFI & 0.972 & Greater than 0.9 \\
AGFI & 0.869 & Greater than 0.9 \\
NFI & 0.912 & Greater than 0.9 \\
NNFI & 0.962 & Greater than 0.9 \\
\hline
\end{tabular}

As we can observe from the results of Table 2, all statistical observations are within acceptable limits, which verify the overall test.

\section{The results}

In this section, we present details of our findings on testing various hypotheses of the survey based on the SEM implementation on LISREL software package. 


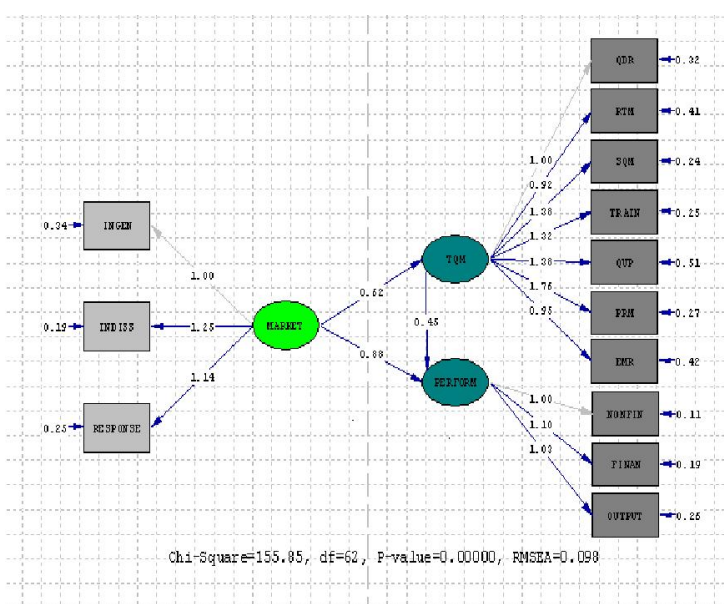

The results of standard values

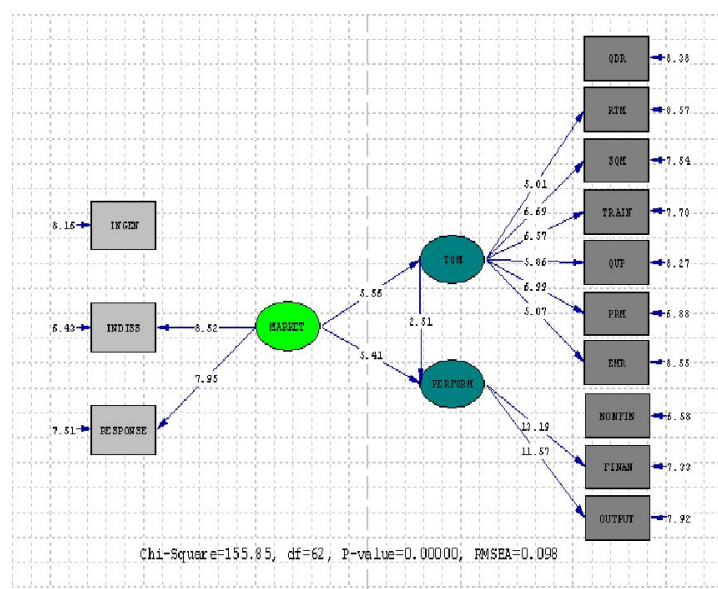

The results of $\mathrm{t}$-student values

Fig. 2. The results of SEM implementation

Based on the results of Fig. 2, all t-values are within acceptable limits and we can confirm four hypotheses of the survey.

\section{Discussion and conclusion}

In this paper, we have presented an empirical investigation to study the impact total quality management as well as market orientation on organizational performance on some Iranian small and medium enterprises (SMEs). The study designs a questionnaire in Likert scale and distributes it among some experts in city of Shiraz, Iran. Table 3 demonstrates the summary of testing the first three hypotheses of the survey.

Table 3

The summary of testing hypotheses of the survey

\begin{tabular}{lcccc}
\hline Hypothesis & $\mathrm{t}$-value & $\beta$ & $\mathrm{R}^{2}$ & Result \\
\hline First & $5.66^{* *}$ & 0.62 & 0.768 & Confirmed \\
Second & $5.41^{* *}$ & 0.88 & 0.678 & Confirmed \\
Third & $2.51^{* *}$ & 0.45 & 0.711 & Confirmed \\
\hline
\end{tabular}

$* *$ Sig $<0.01$

Based on the results of Table 3 we can confirm that the first three hypotheses of the survey. Therefore, market orientation maintains a positive and meaningful impact on TQM on SMEs, market orientation maintains a positive and meaningful impact on organizational performance on SMEs and finally, a good TQM implementation had positive and meaningful impact on organizational performance on SMEs. Because of the significant relationship between market orientation and total quality management and total quality management and organizational performance on one hand and a meaningful relationship between market orientation and organizational performance is significant on the other hand, the last hypothesis of the survey has also been confirmed.

\section{Acknowledgement}

The authors would like to thank the anonymous referees for constructive comments on earlier version of this paper. 


\section{References}

Bayraktar, E., Demirbag, M., Koh, S. C., Tatoglu, E., \& Zaim, H. (2009). A causal analysis of the impact of information systems and supply chain management practices on operational performance: evidence from manufacturing SMEs in Turkey. International Journal of Production Economics, 122(1), 133-149.

Demirbag, M., Koh, S. L., Tatoglu, E., \& Zaim, S. (2006). TQM and market orientation's impact on SMEs' performance. Industrial Management \& Data Systems, 106(8), 1206-1228.

González-Benito, Ó., \& González-Benito, J. (2005). Cultural vs. operational market orientation and objective vs. subjective performance: Perspective of production and operations. Industrial Marketing Management, 34(8), 797-829.

Li, Y., Liu, Y., \& Zhao, Y. (2006). The role of market and entrepreneurship orientation and internal control in the new product development activities of Chinese firms. Industrial Marketing Management, 35(3), 336-347.

Li, Y., Zhao, Y., Tan, J., \& Liu, Y. (2008). Moderating Effects of Entrepreneurial Orientation on Market Orientation-Performance Linkage: Evidence from Chinese Small Firms*. Journal of small business management, 46(1), 113-133.

Liao, S. H., Chang, W. J., Wu, C. C., \& Katrichis, J. M. (2011). A survey of market orientation research (1995-2008). Industrial Marketing Management,40(2), 301-310.

Raju, P. S., Lonial, S. C., \& Crum, M. D. (2011). Market orientation in the context of SMEs: A conceptual framework. Journal of Business Research,64(12), 1320-1326.

Wang, C. H., Chen, K. Y., \& Chen, S. C. (2012). Total quality management, market orientation and hotel performance: the moderating effects of external environmental factors. International Journal of Hospitality Management, 31(1), 119-129. 